\title{
Non-stationary water-level fluctuation in China's Poyang Lake and its interactions with Yangtze River
}

\author{
DAI Xue ${ }^{1,2}$, "WAN Rongrong ${ }^{1}$, YANG Guishan ${ }^{1}$ \\ 1. Key Laboratory of Watershed Geographic Sciences, Nanjing Institute of Geography and Limnology, CAS, \\ Nanjing 210008, China; \\ 2. University of Chinese Academy of Sciences, Beijing 100049, China
}

\begin{abstract}
Seasonal water-level fluctuations (WLF) play a dominate role in lacustrine ecosystems. River-lake interaction is a direct factor in changes of seasonal lake WLF, especially for those lakes naturally connected to upstream and downstream rivers. During the past decade, the modification of WLF in the Poyang Lake (the largest freshwater lake in China) has caused intensified flood and irrigation crises, reduced water availability, compromised water quality and extensive degradation of the lake ecosystem. There has been a conjecture as to whether the modification was caused by its interactions with Yangtze River. In this study, we investigated the variations of seasonal WLF in China's Poyang Lake by comparing the water levels during the four distinct seasons (the dry season, the rising season, the flood season, and the retreating season) before and after 2003 when the Three Gorge Dam operated. The Water Surface Slope (WSS) was used as a representative parameter to measure the changes in river-lake interaction and its impacts on seasonal WLF. The results showed that the magnitude of seasonal WLF has changed considerably since 2003; the seasonal WLF of the Poyang Lake have been significantly altered by the fact that the water levels both rise and retreat earlier in the season and lowered water levels in general. The fluctuations of river-lake interactions, in particular the changes during the retreating season, are mainly responsible for these variations in magnitude of seasonal WLF. This study demonstrates that WSS is a representative parameter to denote river-lake interactions, and the results indicate that more emphasis should be placed on the decrease of the Poyang Lake caused by the lowered water levels of the Yangtze River, especially in the retreating season.
\end{abstract}

Keywords: seasonal water-level fluctuations in lakes; slope of water surface; river-lake interactions; Poyang Lake

\section{Introduction}

Water-level fluctuations (WLF), which reflect the cycles and energy flow in lakes, play an important role in the structure and function of lacustrine ecosystems (Coops et al., 2003;

Received: 2014-05-06 Accepted: 2014-07-02

Foundation: National Basic Research Program of China (“973” Program), No.2012CB417006; National Natural Science Foundation of China, No.41171024; No.41271500

Author: Dai Xue (1988-), MS, specialized in watershed hydrology and ecological effects. E-mail: daixue1224@163.com

"Corresponding author: Wan Rongrong (1977-), PhD and Associate Professor, specialized in watershed eco-hydrology, environmental impacts of land use and cover changes at watershed scale. E-mail: rrwan@niglas.ac.cn 
Poff et al., 2010). WLF, in particular the extent, frequency and duration, affect not only physical processes (e.g. the geomorphological processes of erosion and sedimentation) but also biological processes (e.g. changes within biological populations and communities, variation of biodiversity and habitats) (Leira et al., 2008). The biological effects of WLF are most pronounced in shallow lakes, where even small changes in water levels can result in the transformation of an aquatic environment to an exposed environment, or vice versa (Hudon et al., 2006). Moreover, the biological consequences of WLF in lakes are typically reflected in the shifting dynamics of wetland communities, productivity and spatial distribution (New et al., 2008; Su et al., 2012; Zhang et al., 2012), the dynamics of water quality in accordance with the natural WLF pattern across time (White et al., 2008), as well as the modification of resilience and vulnerability in wetlands, meadows and aquatic ecosystems around the lake (Naselli-Flores et al., 1997). Recently, the pattern of WLF in lakes and their corresponding ecological effects have been found to greatly impact the health of lacustrine ecosystems.

Water levels in shallow lakes naturally fluctuate intra- and inter-annually depending on regional climatic conditions and anthropogenic activities (Coops et al., 2002; Gafny et al., 1999). Hence, WLF occur on different time scales ranging from short-term to annually, inter-annually and inter-decadally (Coops et al., 2003; Hofmann et al., 2008). Although WLF in lakes have been studied on the inter-annual (Lenters, 2001; White et al., 2008) and intra-annual scale (Nishihiro et al., 2009), most previous studies have focused on regulated lake water levels rather than natural, and very few studies have highlighted the ecological responses to the changing pattern of long-term seasonal cycles of lake water levels. Although some seasonal changes in WLF have been noted, e.g. earlier spring runoff due to long-term increases in springtime temperatures in The Great Lakes (Bolsenga et al., 1993), only one specific period of seasonal WLF has been assessed rather than the entire seasonal cycle. Furthermore, lake hydrologic regime in most previous studies was represented by the data collected from only one hydrological station, with no consideration of spatial heterogeneity. Thus, understanding the long-term alternations of seasonal WLF in natural lakes with higher temporal and spatial resolution is essential for further investigation of the associated ecological effects.

The pattern and causes of WLF, which would indirectly generate subsequent ecological consequences, have also been investigated. Recent studies have suggested that seasonal WLF are a natural phenomenon in natural lakes caused by climate (e.g., distribution of annual precipitation and evaporation), morphometry and catchment characteristics (e.g. lake size, depth, basin origin) (Altunkaynak, 2007; Sellinger et al., 2007; Xu et al., 2009). In addition to the inherent environmental variability, WLF have also been influenced by human activities, e.g. land use, land cover alteration via deforestation, urbanization and agricultural expansion associated increased demand on limited groundwater and surface water resources (Guo et al., 2008; Tang et al., 2005) and manipulations of current flow (Coops and Hosper, 2002; Xu and Milliman, 2009). Currently, river-lake interactions, as a direct influence of seasonal lake WLF, have been proposed for lakes naturally connected with upstream and downstream rivers (Guo et al., 2012; Hu et al., 2007). As of yet, the link between river-lake interactions and variations of seasonal lake WLF is not fully understood. The potential reasons may be that 1 ) the hydraulic characteristics of the lake-river systems are too complex, 
and 2) naturally fluctuating lakes are rare in today's world (Wantzen et al., 2008), particularly those lakes with wide ranging seasonal WLF.

The Poyang Lake, the largest fresh water lake in China, is a natural lake that is connected downstream with the Yangtze River, the longest river in China. The dramatic seasonal WLF of the Poyang Lake, including the difference between low water levels in winter and high levels at the height of the summer flood season during which the lake can grow to a staggering eleven meters depth, has formed a unique wetland landscape. The well-known Poyang Lake wetland was one of the first to be included in The Ramsar Convention List of Wetlands of International Importance (The Ramsar Convention, 2012). The lake has multifaceted functions and plays an important role in south China. It is of great value for domestic, agricultural and industrial needs, acts as a commercial fishery and also is essential for ecosystem conservation. Currently, due to limited water supplies, especially in the dry season and other water issues (Jiao, 2009), the Poyang Lake was involved in the National Basic Research Program of China (“973” Program) entitled “Environmental and Ecological Effects and Regulation of the Evolution of River-lake Interaction in the Middle Reach of the Yangtze River” implemented in 2012. These studies have discovered a decrease in size and annual mean water level and a disturbance in the temporal dynamics of the lake level throughout the year. Therefore, it is essential to measure the variation in lake levels on a seasonal scale to predict its future status. Additionally, effects of climate, morphometry and outflow discharge of the Poyang Lake have been detected. Previous studies have suggested that precipitation (reflected in lake inflow) has not resulted in any significant change and the lake volume has remained relatively stable since the 1970s (Liu et al., 2013). Therefore, it is of great value to identify the river-lake interaction effects on seasonal WLF by blocking or reverting lake outflow in an effort to restore natural seasonal hydro-ecological processes as a part of an integrated "973" program of the Poyang Lake Watershed.

WLF in the Poyang Lake are a function of water exchange between the lake and the downstream river in a unique setting composed of rivers downstream and lakes upstream. Particularly, the water holding capacity of the lake mainly depends on its interaction with the downstream river. Previous studies have seldom considered the lake and the downstream river as a whole system on a catchment level, which has overlooked the impact of river-lake interactions on variations in seasonal WLF. Currently, it is a challenge to study river-lake interaction quantitatively with a reliable variable since semi-distributed or distributed hydrological river-lake models for this complex setting with lakes upstream and rivers downstream are not yet available (Guo et al., 2012). Guo and Hu (Guo et al., 2011; Hu et al., 2007) defined two situations: the impact of the lake on the river and the river's influence on the lake, by exploring conditions composed of a combination of observational data. Clearly, the application of discrete and qualitative variables has a limited ability to represent physical processes. Zhao et al. (2011) constructed a composite indicator $\mathrm{I}_{\mathrm{p}}$, also referred to as a river-lake water exchange coefficient, which includes discharge of the lake empting into downstream river and duration of the river flowing back into the lake in the year. This semi-quantitative coefficient cannot directly demonstrate the cause-effect relationship between the lake and the downstream river. Lenters (2001) described river-lake interaction from a hydrological water balance perspective by the fluctuation of lake levels responding to exchanges between bodies of water upstream and downstream. Dai et al. (2015) studied river-lake interaction by measuring the stage-discharge relationship. However, all of these 
methods lack precision and are indirect. Hence, it is critical to construct a representative parameter to more precisely measure river-lake interaction.

The overarching goal of this research is to address how seasonal WLF have changed and how these changes have been impacted by river-lake interaction in the case of the Poyang Lake and the downstream Yangtze River. Results of this study will help water resource managers make informed decisions about how to conserve the largest freshwater lake watershed in China. It is our hope that it will provide reference for further studies on the health of river-lake relationships as well as evaluations of the dynamic water security of lakes associated with river-lake water exchanges in similar watershed systems. Our study devised a methodology to link WLF and river-lake interactions that could be useful for further watershed management not only in the China's Poyang Lake region but also in other similar areas around the world.

To investigate seasonal WLF in China's Poyang Lake and the related river-lake interactions, the following steps were taken: (1) $L$-function was used to detect the spatial point pattern of hydrological stations to ensure spatially random samplings that reflected the overall water level of the lake; (2) the surfaces of the lake during different seasons of the year were interpolated using the Ordinary Kriging model at the randomly distributed stations, and the lake levels were compared during the same season in different years (2003-2011 and 1980-2002) to determine the seasonal WLF patterns; (3) the Water Surface Slope (WSS) in various areas of the lake was compared; (4) the variation in river-lake interaction and its impacts on the seasonal WLF were analyzed.

\section{Datasets and methods}

\subsection{Study region}

The Poyang Lake $\left(115^{\circ} 49^{\prime} \mathrm{E}-116^{\circ} 46^{\prime} \mathrm{E}, 2^{\circ} 24^{\prime} \mathrm{N}-29^{\circ} 46^{\prime} \mathrm{N}\right)$, with a drainage area of 162,225 $\mathrm{km}^{2}$, is located at the southern bank of the middle reaches of the Yangtze River. The lake receives inflow from five major tributaries and then drains north into the Yangtze River at Hukou (Figure 1). The lake receives backflow from the Yangtze River at the height of the flood season. The climate is typically warm, humid subtropical and prone to monsoons. It has an annual mean temperature of $16.5-17.8^{\circ} \mathrm{C}$ and an annual mean precipitation of 1400-1700 mm. The complex processes of inflow, outflow and backflow lead to dramatic seasonal water-level fluctuations. Therefore the water surface of the lake ranges from 907.7 to $3752.7 \mathrm{~km}^{2}$, with a mean of $2388.0 \mathrm{~km}^{2}$ and one standard deviation of $735.0 \mathrm{~km}^{2}$, according to available Landsat images (from 1973 to 2010) (Liu et al., 2012; Liu et al., 2013), leading to the unique landscape that has been described as "flooding like the sea, drying like thread."

The Poyang Lake is characterized by seasonal WLF that can be divided into four distinct periods, the dry season (from December to March,), rising period (from April to June, the rising season), the flood season (peak period, from July to September) and retreating period (from October to November). For example, at Xingzi station from 1951 to 2011 (Figure 2), the mean water level in the dry season was 9.85 [9.81, 9.89] $\mathrm{m}$ (the range inside the parenthesis represents the $95 \%$ confidence intervals), while the mean water level during the flood season was 16.73 [16.67, 16.79] $\mathrm{m}$. The annual water level amplitude averaged up to 11.01 


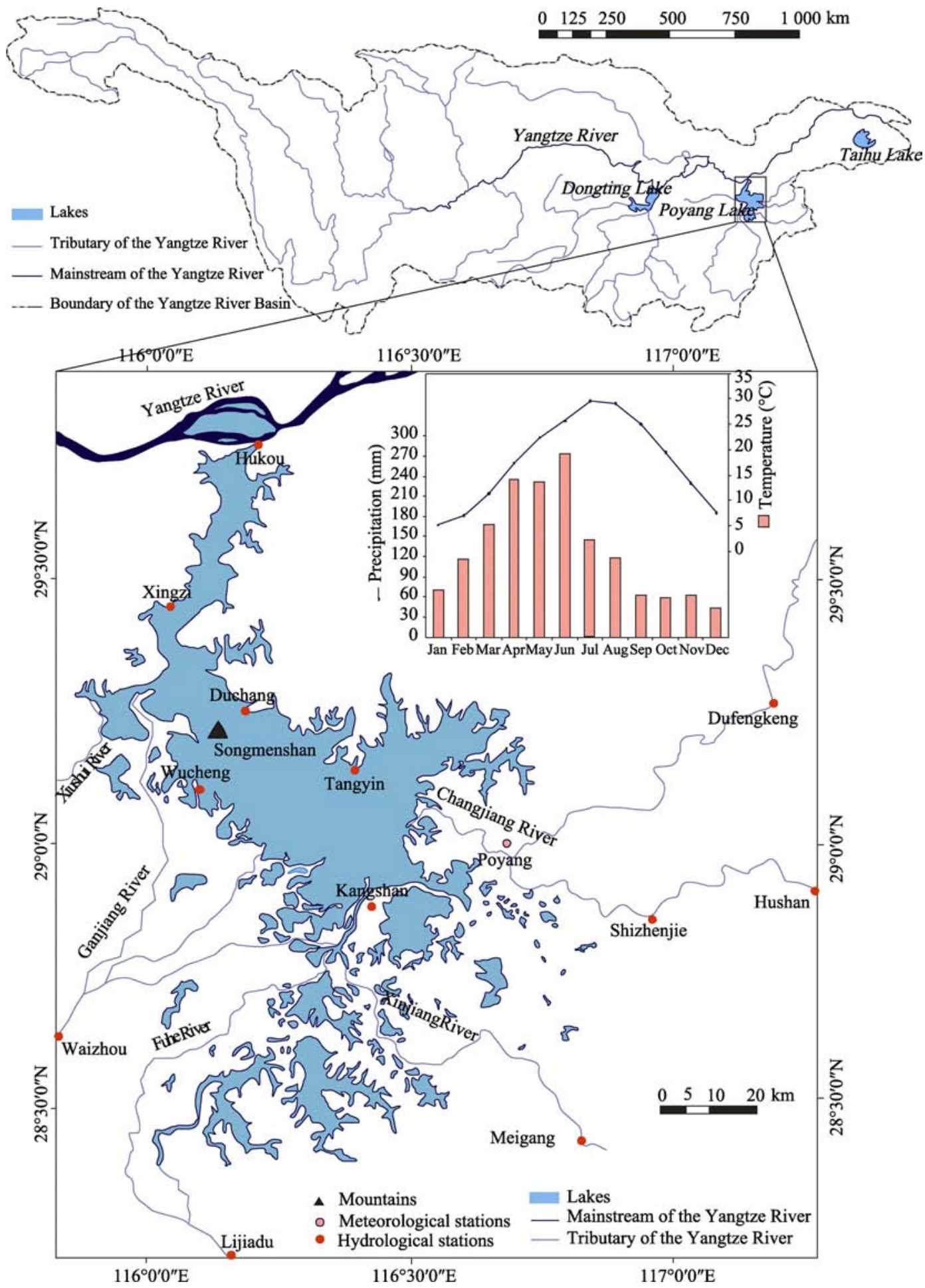

Figure 1 Location and geological map of the Poyang Lake

(Map showing the setting of the Poyang Lake and its five tributaries and the river-lake system. The monthly mean temperature and precipitation of the lake basin (represented by data from the Poyang meteorological station) during 1957-2010 is also shown by the inset.) 


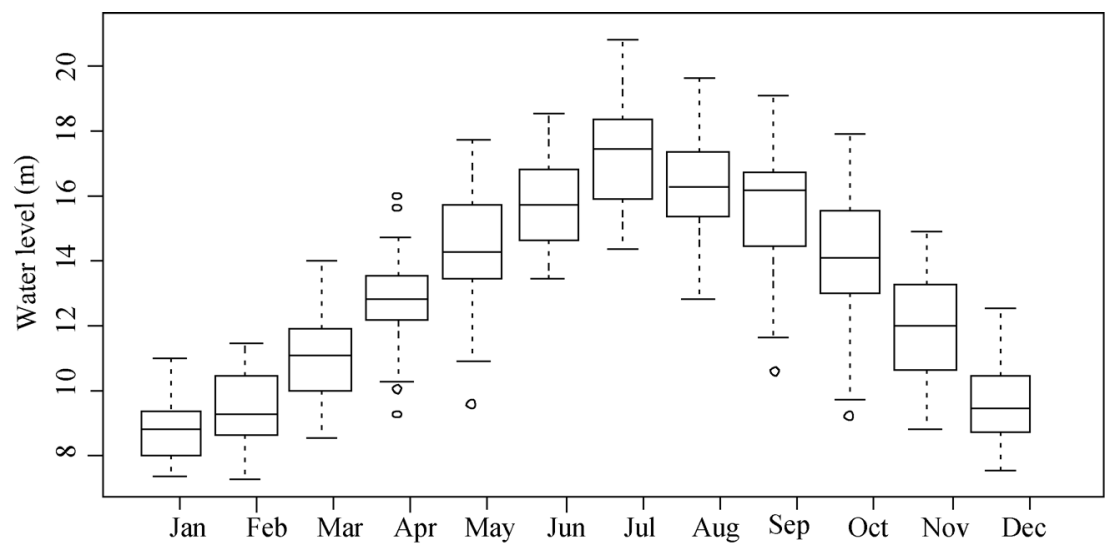

Figure 2 The monthly mean water level at Xingzi Station during 1951-2011

m $(p<0.001)$. During the transition periods between these two seasons, lake levels rose or fell rapidly. The water level in the retreating period was 13.17 [13.09, 13.24] $\mathrm{m}$, and 14.53 [14.47, 14.59] $\mathrm{m}$ in the rising period. Since 2003, the magnitude of seasonal WLF have changed profoundly, e.g. the driest time with the lowest water level is occurring earlier each year and the lowest water level record (since 1951) continues to drop (Yang, 2012).

The dramatic seasonal fluctuations of water levels are influenced by both runoff from the upstream watershed via five major tributaries and the water interchange with the Yangtze River. Particularly, the water holding capacity of the Poyang Lake mainly depends on the varying water exchange between the lake and Yangtze River. Usually the rainy season in the Poyang Lake Watershed and the upstream Yangtze River is not synchronized. During the rainy season, Poyang is flooded from the five sub-watersheds which feed into the lake and rapidly increase its water level (Shankman et al., 2006), which also has a strong impact on the river. During the rainy season upstream from the Yangtze River, i.e. the flood season for the lake, the rising river level blocks the outflow of the Poyang Lake (Guo et al., 2011), leading to peak lake levels and flooding. The seasonal migration of the rain belt is primarily due to the Asian monsoons (Ding, 1994; Wang et al., 2002). In the retreating season, the declining water level in the Yangtze River weakens its blocking effect on the lake, which could eventually cause the lake to recede. From December to the following March, i.e. the dry season for the lake, the lake level falls even lower. This dryness does not subside until late March and early April when rainfall increases the lake watershed. The pattern of river-lake interactions varies according to the seasons, leading to seasonal water-level fluctuations of the lake. Above all, the effective mechanism of river-lake interaction is that the altering of the Yangtze River level can change the blocking force of the river on the outflows from the Poyang Lake (Chen, 1994; Hu et al., 2007; Shankman et al., 2006; Wang and LinHo, 2002).

\subsection{Data sources}

Data required in this study included daily water level observations of the Poyang Lake from 1980-2011 derived from twelve hydrological stations as well as the meteorological data of the basin, which were obtained from the Hydrological Bureau of Jiangxi Province and the National Meteorological Information Center(http://www.nmic.gov.cn/), respectively. The 
water levels were measured using the reference elevation system of Wusong (approximately 1.97 m a.s.l., level Huanghai National Height Datum elevation system). The locations of these hydrological stations are shown in Figure 1: Hukou station is located at the outlet of the Poyang Lake, the five stations (Xingzi, Duchang, Kangshan, Wucheng, Yintang) are located at the main lake, while six stations (Waizhou, Lijiadu, Meigang, Hushan, Dufengkeng) are control stations for the five main tributaries.

These daily data were used to calculate corresponding seasonal mean values, which were applied to interpolate corresponding seasonal lake water surfaces and were further adopted to represent the lake level in order to take spatial heterogeneity into account. Circumstances in 1980-2002 were taken as benchmarks against which to explore the variation of seasonal WLF in 2003-2011, since our previous study discovered an abrupt change in lake levels in 2003 compared to a period of 21 years (from 1980 to 2011) (Dai et al., 2015).

Moreover, those daily water levels in Hukou, Xingzi, Duchang and Kangshan stations were used to calculate the WSSs of different areas of the Poyang Lake, which were used to detect variations in river-lake interaction. The lake is divided into two regions by the Songmenshan Mountain. The northern region, Hukou-Xingzi of the lake is the water channel which joins the Yangtze River. It has a length of $40 \mathrm{~km}$ and the width of 3-5 km (the narrowest point is $2.8 \mathrm{~km}$ ). The southern region, Duchang-Kangshan, is the main lake area. It has a length of $133 \mathrm{~km}$ and the furthest width of $74 \mathrm{~km}$. WSS of Hukou-Xingzi is directly affected by interactions between the Yangtze River and the Poyang Lake, while the WSS of Duchang-Kangshan lake region is directly impacted by the river-lake interactions via variation in water storage volume.

\subsection{Determining spatial point pattern of the hydrological stations}

The spatial point pattern of the sample points must be determined before they can be used to calculate the estimated variance and sample support effects in certain areas. Since clustered sample points may lead to a spatially-biased result with high bias, these hydrological stations utilized to interpolate the overall lake water surfaces should be spatially randomly sampled to ensure the smallest possible bias in the estimates. There are many techniques for statistical analysis of spatial point patterns, including density-based methods (such as the quadrant analysis and the Two-Dimensional Kernel Density Estimation) and distance-based methods (such as nearest neighbor indicator, $G$ function, $F$ function and $K$ function). Each has its own strengths and limitations for detecting spatial point patterns (Gelfand, 2010). However, $L(r)$, the transformation of Ripley's reduced second moment function $K(r)$, can test point patterns of different scales by using a stabilizing variance of the estimator, even with increasing distance $r$. Therefore, $L(r)$ is one of the most widely used spatial point pattern detection methods and is therefore highly recommended (Besag, 1977). The general steps for utilizing the $L$-function are as follows:

For a stationary point process $X$, within a distance $r$, the estimates of $L(r)$ are of the form:

$$
L(r)=\operatorname{sqrt}\{(a /(n *(n-1))) * \operatorname{sum}[i, j] I(d[i, j] \leqslant r) e[i, j]) / \pi\}
$$

where $a$ is the window area, $n$ is the number of data points, and the sum is taken over all ordered pairs of points $i$ and $j$ in $X$. The term $d[i, j]$ is the distance between the two points, and $I(d[i, j] \leqslant r)$ is the indicator that equals 1 when the distance is less than or equal to $r$. 
Here $e[i, j]$ is the edge correction weight (The translation correction method (Ohser, 1983) was applied to achieve edge correction).

The estimate of $L$ should be compared to the true value of $L$ for a complete spatial random (CSR) point process, when $L(r)=r$. Deviations between the empirical and theoretical $L$ curves may suggest spatial clustering or spatial regularity. A grouping of summary statistics was calculated based on simulations. In this paper, 99 simulations of CSR with the same intensity as the pattern were generated; that is, a significant level of $\alpha=0.05$ was used. If $L_{o b s}(r)$ is greater than the $L_{\text {theo }}(r)$ at a distance $r, X$ would be more clustered than a CSR process within the distance $r$, and vice versa. Additionally, if $L_{o b s}(r)$ is greater than the upper critical grouping, $L_{h i}(r)$, at a distance $r, X$ would be a cluster point process well within the distance $r$. Otherwise, if $L_{o b s}(r)$ is less than the lower critical grouping, $L_{l o}(r)$, at a distance $r$, $X$ would be a regular point process well within the distance $r$.

\subsection{Interpolation of lake water surfaces}

Based on the CSR test at the hydrological stations, the water level data collected from these twelve randomly distributed stations (noted in the first part of the Results section) were used to interpolate the lake water surface for spatial analysis. There are two main types of interpolation techniques: deterministic and geostatistical. Deterministic interpolation techniques create surfaces from measured points based on either the extent of similarity (Inverse Distance Weighted) or the degree of smoothing (Radial Basis Functions). Geostatistical interpolation techniques (Kriging) utilize the statistical properties of the measured points; thus, they are capable of not only producing a prediction but also the error rate of that prediction. For this reason, the Kriging model was applied in this study. The model is expressed in the following simple mathematical formula:

$$
Z(s)=\mu(s)+\varepsilon(s)
$$

where $z(s)$ is the variable water level of the lake, classified into trend $\mu(s)$ and a random, auto-correlated error form $\varepsilon(s)$. The symbol s simply indicates the location. According to properties of fluids, the lake water surface is homogeneous and the value of the water levels at different points in the lake should be a simple constant; that is, $\mu(s)=\mathrm{m}$ for all locations $s$, and $\mu$ is unknown. This is the model on which ordinary Kriging is based. Therefore, the Ordinary Kriging Model was used in this study. Errors of prediction were accessed by Mean Standard Error (MSE). The basic principle of the method is introduced in the following equation:

$$
\hat{z}\left(s_{0}\right)=\sum_{i}^{n} \lambda_{i} z_{i}
$$

where $z_{i}$ is the measured water level at $s_{i}$, and $\lambda_{i}$ is the undetermined coefficient, which can be calculated by the following equation set:

$$
\left\{\begin{array}{c}
\sum_{j}^{n} \lambda_{j} \gamma\left(z_{i}, z_{j}\right)+\mu=\gamma\left(z_{i}, z_{j}\right) \\
\sum_{j}^{n} \lambda_{j}=1
\end{array}\right.
$$

where $\gamma$ is the semivariogram: 


$$
\gamma(h)=\frac{1}{2 n(h)} \sum_{p=1}^{n(h)}\left[Z\left(s_{p}\right)-Z\left(s_{p}+h\right)\right]
$$

where $n(h)$ is the number of point pairs whose distance is equal to $h$. The Spherical model was used to estimate the semivariogram in this study.

\subsection{WSS and river-lake interaction}

As mentioned above, currently, a challenge of river-lake interaction research is to establish a reliable variable to quantify this interaction. In this study, river-lake interactions were measured employing the WSS, which reflects direct and continuous interactions between the river and the lake. Therefore, it should be a suitable method for quantitatively determining the level of the river-lake interaction. Moreover, WSS is practical, since it only requires the observation data of water levels essentially. Thus, WSS is a better choice than the other parameters mentioned above. The principle of WSS is explained in the equation below.

WSS is defined as a vertical gradient per unit of horizontal length in the downstream direction, usually denoted in units of millionths of a meter $(\% / 000)$. It can be calculated from the drop in water surface elevation between two points (i.e. stations) divided by the horizontal distance between the two points. Since water surface profiles are not available for the Poyang Lake, the WSS was calculated by the following mathematical formula:

$$
S=\frac{Z_{u}-Z_{l}}{l} \times 10000
$$

where $S$ is the WSS (in ${ }^{0} / 000$ ); $Z_{u}$ and $Z_{l}$ are the water levels (in meters) obtained at the upstream station and the downstream station, respectively; $l$ is the distance between the two stations.

Additionally, seasonal mean lake levels were used here since short-term effects (such as seiches induced by wind) and transverse slope of water surface caused by flood current can be eliminated through the use of seasonal mean (rather than daily) lake levels, which were found to be positively correlated with the results.

\section{Results and discussion}

\subsection{Spatial point pattern of hydrological stations}

The detection result of hydrological stations spatial distribution pattern is shown in Figure 3. The $L_{o b s}(r)$ is less than $L_{\text {theo }}(r)$ and $L_{l o}(r)$ within the distance $18.5 \mathrm{~km}$, which suggests significant spatial regularity within these hydrological stations. Beyond the range of $18.5 \mathrm{~km}$, the $L_{o b s}(r)$ is less than $L_{t h e o}(r)$ in the grouping, which indicates that these hydrological stations follow a random point process with a slightly scattered trend.

Obviously, these twelve hydrological stations in our study are spatially randomly distributed around the Poyang Lake. Moreover, in terms of the complexity of the river-lake system, five of these stations are located at the main lake area, and the rest are either the control stations of tributaries or the outlet control stations of the lake. To summarize, these stations in the interpolation model are highly representative, so even with a small sample, the water level data derived from these stations can be used to predict the lake water surface with high accuracy. 


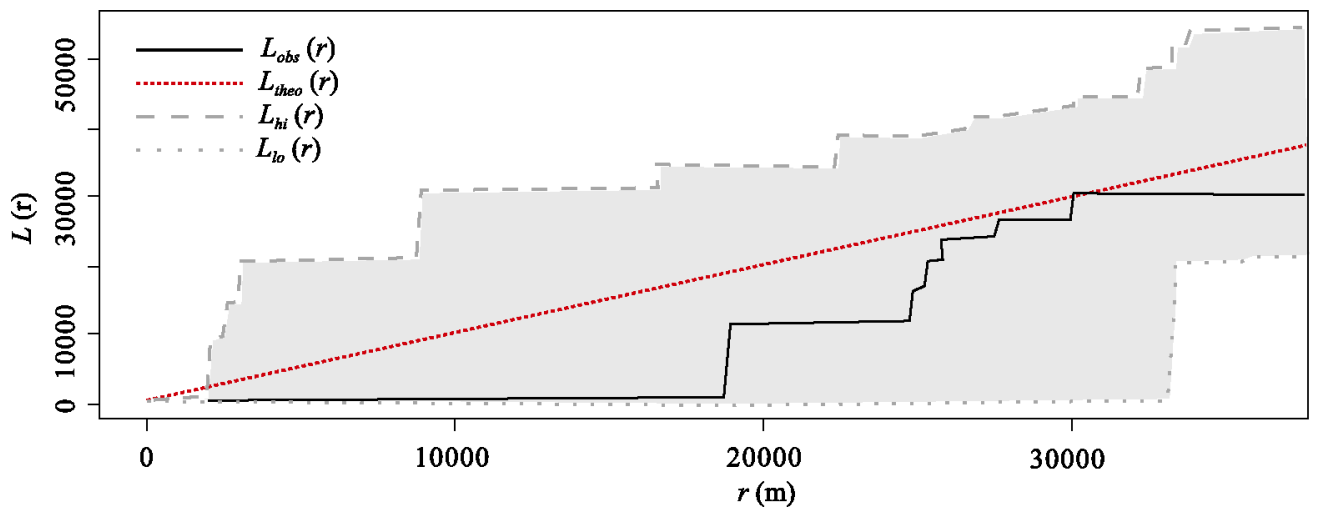

Figure 3 The spatial point pattern of hydrological stations in the Poyang Lake tested by the $L$-function

\subsection{Variation of seasonal WLF in the Poyang Lake}

Water level variations in different seasons are depicted in Figure 4. It should be noted that only the variations in lake levels were shown, without considering the corresponding area of the water surface. The lake water surface images, which were extracted from the Normalized Difference Water Index (NDWI) by means of remote sensing (Liu et al., 2012; Liu et al., 2013), were placed over static contour maps to show the mean water level of corresponding seasons. For example, the lake water surface during the low water level period on January 28, 2003 was $10.5 \mathrm{~m}$, which was close to the mean for this period. The same situation



Figure 4 Mean lake-levels of the rising, flood, retreating, and dry season during periods of 1980-2002 and 2003-2011 



Figure 5 The mean water surface slope of Hukou-Xiangzi lake region (a) and Duchang-Kangshan lake region (b) in 1980-2002 and 2003-2011

occurred on March 10, 2003 during the rising period in which the mean level was $12.8 \mathrm{~m}$, $16.5 \mathrm{~m}$ on September 13, 2003 for the peak period and $13.3 \mathrm{~m}$ on October 25, 2003 for the retreating period. The outline indicates the largest overflow of the Poyang Lake (Liu et al., 2012; Liu et al., 2013).

The interpolation results (Figure 4) show that during each of the four seasons, lake levels experienced a significant downward shift in 2003-2011 compared to 1980-2002. Specifically, since 2003 they have dropped by 0.69 [0.39-0.99] m, 1.30 [0.92-1.48] $\mathrm{m}, 1.49$ [0.97-2.00] $\mathrm{m}$ and 0.64 [0.35-0.93] $\mathrm{m}$ during the rising, flood, retreating, and dry season, respectively. It is important to note that a different magnitude of variation over the seasons indicates important changes in the seasonal WLF of the Poyang Lake. The water level variation during the retreating season was the most significant, followed by that of the flood season, the dry season and the rising season. These changes have impacted the shape of the hydrograph depicting annual flow.

The magnitude of variation of lake-levels was most pronounced between the upper and lower regions of the Poyang Lake. The contours with lower values are usually found farther upstream than the contours with higher values during all four periods. These negative trends (the dropping of the lake level) for each season weakened quickly upstream of the Poyang Lake and nearly diminished in the southern region, indicating that river-lake interaction rather than the inflow from main tributaries has more of an impact on the shift of the seasonal WLF. This result is consistent with those obtained in previous studies (Liu et al., 2013), which indicates that the precipitation in the lake watershed did not undergo any significant change.

Since the movement of water is continuous, there will be constant variations in WLF throughout the year. At different times there will be different magnitudes of variation since the last major disturbance. Therefore, taking the order of variations in magnitude into account, we can infer that transformation from a gradual reduction to a rapid reduction of water during the retreating period was the major disturbance of seasonal WLF of the Poyang 
Lake since 2003. More specifically, rapid reduction of lake-levels in the retreating period has led to the expansion and increased severity of the dry season. Furthermore, this change has resulted in a decrease of water levels in the following rising period and lowered peak water levels in the next flood season.

These results revealed that (1) the magnitude of seasonal WLF have changed considerably since 2003: The largest water level reduction occurred during the retreating season which could not be offset during the rising or flooding seasons, resulting in further reduction of annual mean water level; (2) the Poyang Lake shows a pronounced seasonal WLF with later rising and earlier reduction and a lower flood water level (on an annual basis), which resulted in a very distorted shape and magnitude of the diurnal hydrograph than it was in 1980 to 2002; (3) the alteration of hydrologic regime in the retreating season triggered these series of changes; and (4) river-lake interactions, rather than inflow from tributaries, was mainly responsible for these variations in magnitude of seasonal WLF. The question of how the variations in magnitude of seasonal WLF have responded to the varying river-lake interactions is delineated in the next section.

\subsection{Variations of river-lake interaction and the corresponding seasonal WLF}

Before describing the river-lake interactions it is important to discuss the physical impact of WSS in various areas of the lake. In the southern Duchang-Kangshan, the main lake region, WSS reflects the rate of water storage change. A steeper WSS causes a sharp reduction in water storage capacity and vice versa. While in the northern Hukou-Xingzi region in which the water channel joins the Yangtze River, WSS reflects the force that the Yangtze River and the Poyang Lake exert on each other. Generally, the WSS of Hukou-Xingzi is positive, which forces lake water into the river. In this case, considering the decline of the lake level mentioned above, gentler WSS indicates that both river and lake levels have dropped, and the magnitude of the drop in lake levels is greater than that of the river. However, the WSS of Hukou-Xingzi can be zero or even negative during flood season when the rising river flow and water level exert large amounts of pressure on the lake which reduces its outflow or even reverses the flow. In this case, WSS increasing to a positive value would mean that the impact of the river on the lake would abate due to reverse flow. Additionally, the variation in WSS of the Duchang-Kangshan region of the lake is primarily associated with the Hukou-Xingzi area. In other words, the WLF of the Poyang Lake is strongly influenced by the varying river-lake interactions.

Effects of the river-lake interactions on seasonal WLF of the Poyang Lake are shown in Figure 5. Daily WSS from 1980-2002 (green dashed line) and 2003-2011 (red solid line) are also compared in Figure 5. During 2003-2011, no significant change of WSS occurred during the flood season. While WSS dramatically steepened from the beginning of the retreating season in the Duchang-Kangshan lake region, which means an accelerated reduction in the Poyang Lake which increased water velocity and outflow. At this time, there was also a severe drop in WSS in the Hukou-Xingzi lake region, meaning that lowered water levels in the Yangtze River would weaken the blocking effects on the lake outflow, resulting in additional lake water flowing into the river and a sizable drop in the lake level. Obviously, the river-lake interaction pattern would be the driving force of the variation in hydrologic regime of the lake.

This river-lake interaction pattern, mentioned above continued until the following rising 
season. However, there was significant variation trend of WSS in the two regions of the lake. The largest shift of WSS in the Duchang-Kangshan lake region ranged from roughly $0.11 \%$ in $1980-2002$ to $0.49 \%$ in $2003-2011$ during the retreating season, then the range shrank in the following dry season. The drop in the Hukou-Xingzi lake region continued from the very beginning of the retreating season until late into the dry season. These phenomena indicate that in the following dry season, the Poyang Lake lost a great deal of its water storage capacity and reduced lake water flow to the Yangtze River, because the river-level remained much lower in this season than in previous years and lake water continued to flow into the river at a rapid pace.

More specially, river-lake interaction in the flood season is very dramatic with high water levels and significant discharge to both the Yangtze River and the Poyang Lake. Although the WSS is close to zero, even a slight change in WSS could create either a significant inflow or backflow. Thus, even though there was no dramatic variation in WSS during the flood season since 2003 (Figure 5), the trend it revealed was remarkable. During the period from 2003 to 2011, WSS in the Hukou-Xingzi lake region was steeper than in 1980-2002, which also indicates the river's weakening resistance or backflow impact on the lake flow during flood season.

Depending on the structure of lake and the water flow, the variation on seasonal WLF in one part of the lake can shift to another. Thus we can infer that the lowered Yangtze River level leads to weakening of resistance or backflow effects on the lake flow at the junction of the river and lake throughout the year. This affects the entire lake and creates a severe loss of lake water storage capacity.

To summarize, these results indicate that in 2003-2011, the variation of river-lake interaction triggered the variation in seasonal WLF. The lowered river levels have depleted the lake's water storage capacity, especially in the retreating season. The results were found to be consistent with previous studies (Dai et al., 2008) which suggested that increased the Poyang Lake outflow into the Yangtze River in the dry season led to the situation that there was no drought in the drought season in the lower reaches of the Yangtze River in the extreme drought year 2006. Recently, Zhang Qi et al. also demonstrated that, compared to climate variability impacts on the lake catchment, modifications of the drainage effect of the Yangtze River have had a much greater impact on the seasonal (September-October) dryness of the lake (Zhang et al., 2014).

\section{Conclusions}

A representative parameter, the water surface slope (WSS), was constructed to denote river-lake interaction. Variation of seasonal water level fluctuations in China's Poyang Lake was investigated by comparing the lake levels during each season before and after the year 2003. In addition, the reasons for these fluctuations were explored by comparing the WSS of various regions of the lake during each season between 2003-2011 and 1980-2002. According to our analysis, the following conclusions can be drawn.

(1) The magnitude of seasonal WLF in the Poyang Lake has changed considerably since 2003. The reduction transformed from steady to rapid during the retreating season, which was the cause of the changes in seasonal WLF. Specifically, rapid reduction of lake levels during the retreating season led to more extensive dryness in the following dry season. 
Hence, greater inflow was needed to raise the lake level during the rising season, leading to lower levels in the rising season as well as the following flood season, which further resulted in reductions of annual mean lake levels. All the changes above make the peak value lower and the corresponding slope steeper, which final resulted in a much distorted shape and magnitude of the diurnal hydrograph than it was from 1980 to 2002.

(2) The changes in the river-lake interaction have been evidenced by an enormous shift of WSS since 2003, which was the trigger mechanism for the variations in seasonal WLF. More specifically, the lowered downstream river level has severely decreased the lake's water storage capacity, which is crucial from the very beginning of the retreating season until late in the rising season. Moreover, this pattern of river-lake interaction was especially remarkable in the reduction. To a certain extent, because the underlying decline of the Yangtze River level may continue, it would be wise to include studies of lowered lake-levels in the future to aid management planning.

(3) This study demonstrates that WSS is a representative parameter to denote river-lake interactions. The WSS used in this study took into account the interactions between lake and river quantitatively, and the change of WSS was inferred to be the cause of variation in seasonal WLF.

The results can enrich the existing knowledge of factors that impact seasonal WLF (e.g. factors recognized widely, precipitation, evapotranspiration, etc.) and provide reference for policy makers and regulatory authorities in this largest freshwater lake watershed in China. Furthermore, it will provide reference of how to promote healthy river-lake interactions and evaluate methods for studying dynamic river-lake water interchanges in analogous watershed systems.

\section{References}

Altunkaynak A, 2007. Forecasting surface water level fluctuations of Lake Van by artificial neural networks. Water Resources Management, 21(2): 399-408.

Besag J, 1977. Contribution to the discussion of Dr. Ripley’s paper. JR Stat. Soc. B, 39(2): 193-195.

Bolsenga S J, Norton D C, 1993. Great Lakes air temperature trends for land stations, 1901-1987. Journal of Great Lakes Research, 19(2): 379-388.

Chen G T J, 1994. Large-scale circulations associated with the East-Asian Summer Monsoon and the Mei-Yu over South China and Taiwan. Journal of the Meteorological Society of Japan, 72(6): 959-983.

Coops H, Beklioglu M, Crisman T L, 2003. The role of water-level fluctuations in shallow lake ecosystems-workshop conclusions. Hydrobiologia, 506(1-3): 23-27.

Coops H, Hosper S H, 2002. Water-level management as a tool for the restoration of shallow lakes in the Netherlands. Lake and Reservoir Management, 18(4): 293-298.

Dai X, Wan R, Yang G et al., 2015. Temporal variation of hydrological rhythm in Poyang Lake and the associated water exchange with the Yangtze River. Scientia Geographica Sinica, http://www.cnki.net/kcms/detail/ 22.1124.P.20140428.0926.007.html. (in press) (in Chinese)

Dai Z J, Du J Z, Li J F et al., 2008. Runoff characteristics of the Changjiang River during 2006: Effect of extreme drought and the impounding of the Three Gorges Dam. Geophysical Research Letters, 35(7).

Ding Y, 1994. Monsoons over China. New York: Springer, 419 pp.

Gafny S, Gasith A, 1999. Spatially and temporally sporadic appearance of macrophytes in the littoral zone of Lake Kinneret, Israel: Taking advantage of a window of opportunity. Aquatic Botany, 62(4): 249-267.

Gelfand A E, 2010. Handbook of Spatial Statistics. Boca Raton: CRC Press.

Guo H, Hu Q, Jiang T, 2008. Annual and seasonal streamflow responses to climate and land-cover changes in the Poyang Lake basin, China. Journal of Hydrology, 355(1-4): 106-122.

Guo H, Hu Q, Zhang Q, 2011. Changes in hydrological interactions of the Yangtze River and the Poyang Lake in China during 1957-2008. Acta Geographica Sinica, 66(5): 609-618. (in Chinese).

Guo H, Hu Q, Zhang Q et al., 2012. Effects of the Three Gorges Dam on Yangtze River flow and river interaction 
with Poyang Lake, China: 2003-2008. Journal of Hydrology, 416: 19-27.

Hofmann H, Lorke A, Peeters F, 2008. Temporal scales of water-level fluctuations in lakes and their ecological implications. Hydrobiologia, 613(1): 85-96.

Hu Q, Feng S, Guo H et al., 2007. Interactions of the Yangtze River flow and hydrologic processes of the Poyang Lake, China. Journal of Hydrology, 347(1/2): 90-100.

Hudon C, Wilcox D, Ingram J, 2006. Modeling wetland plant community response to assess water-level regulation scenarios in the Lake Ontario-St. Lawrence River basin. Environmental Monitoring and Assessment, 113(1-3): 303-328.

Jiao L, 2009. China scientists line up against dam that would alter protected wetlands. Science, 326(5952): 508-509.

Leira M, Cantonati M, 2008. Effects of water-level fluctuations on lakes: An annotated bibliography. Hydrobiologia, 613(1): 171-184.

Lenters J D, 2001. Long-term trends in the seasonal cycle of Great Lakes water levels. Journal of Great Lakes Research, 27(3): 342-353.

Liu Y, Song P, Peng J et al., 2012. A physical explanation of the variation in threshold for delineating terrestrial water surfaces from multi-temporal images: Effects of radiometric correction. International Journal of Remote Sensing, 33(18): 5862-5875.

Liu Y, Wu G, Zhao X, 2013. Recent declines in China's largest freshwater lake: Trend or regime shift? Environmental Research Letters, 8(1): 014010.

Naselli-Flores L, Barone R, 1997. Importance of water-level fluctuation on population dynamics of cladocerans in a hypertrophic reservoir (Lake Arancio, south-west Sicily, Italy). Cladocera: The Biology of Model Organisms. Springer, 223-232.

New T Xie Z Q, 2008. Impacts of large dams on riparian vegetation: Applying global experience to the case of China's Three Gorges Dam. Biodiversity and Conservation, 17(13): 3149-3163.

Nishihiro J, Washitani I, 2009. Quantitative evaluation of water-level effects on "regeneration safe-sites" for lakeshore plants in Lake Kasumigaura, Japan. Lake and Reservoir Management, 25(2): 217-223.

Ohser J, 1983. On estimators for the reduced second moment measure of point processes. Series Statistics, 14(1): 63-71.

Poff N L, Richter B D, Arthington A H et al., 2010. The ecological limits of hydrologic alteration (ELOHA): A new framework for developing regional environmental flow standards. Freshwater Biology, 55(1): 147-170.

Sellinger C E, Stow C A, Lamon E C et al., 2007. Recent water level declines in the Lake Michigan-Huron System. Environmental Science \& Technology, 42(2): 367-373.

Shankman D, Keim B D, Song J, 2006. Flood frequency in China's Poyang Lake region: Trends and teleconnections. International Journal of Climatology, 26(9): 1255-1266.

Su X L, Zeng B, Huang W J et al., 2012. Effects of the Three Gorges Dam on preupland and preriparian drawdown zones vegetation in the upper watershed of the Yangtze River, P.R. China. Ecological Engineering, 44: $123-127$.

Tang Z, Engel B, Pijanowski B et al., 2005. Forecasting land use change and its environmental impact at a watershed scale. Journal of Environmental Management, 76(1): 35-45.

The Ramsar Convention, 2012. The List of Wetlands of International Importance, 25 April 2012 (available from: www.ramsar.org/pdf/sitelist.pdf, accessed on 8 August 2012).

Wang B, LinHo, 2002. Rainy season of the Asian-Pacific summer monsoon. Journal of Climate, 15(4): 386-398.

Wantzen K M, Junk W J, Rothhaupt K-O, 2008. An extension of the floodpulse concept (FPC) for lakes. Hydrobiologia, 613(1): 151-170.

White M S, Xenopoulos M A, Hogsden K et al., 2008. Natural lake level fluctuation and associated concordance with water quality and aquatic communities within small lakes of the Laurentian Great Lakes region. Hydrobiologia, 613(1): 21-31.

Xu K, Milliman J D, 2009. Seasonal variations of sediment discharge from the Yangtze River before and after impoundment of the Three Gorges Dam. Geomorphology, 104(3): 276-283.

Yang G, 2012. Water issues in the Yangtze River and its formation causes and controlling strategies. Resources and Environment in the Yangtze Basin, 21(7): 821-830. (in Chinese)

Zhang Q, Li L, Wang Y G et al., 2012. Has the Three-Gorges Dam made the Poyang Lake wetlands wetter and drier? Geophysical Research Letters, 39.

Zhang Q, Ye X C, Adrian D W et al., 2014. An investigation of enhanced recessions in Poyang Lake: Comparison of Yangtze River and local catchment impacts. Journal of Hydrology, 517: 425-434.

Zhao J K, Li J F, Yan H et al., 2011. Analysis on the water exchange between the main stream of the Yangtze River and the Poyang Lake. In: 2011 3rd International Conference on Environmental Science and Information Application Technology Esiat., 10(Part C): 2256-2264. 